\title{
Thiết kế bảng hỏi nghiên cứu đảm bảo tính khoa học
}

\author{
Hồ Mạnh Toàn \\ A.I. for Social Data Lab (AISDL)
}

Hà Nội, 10-12-2018

SSHPA (10-12-2018; https://sc.sshpa.com/post/4355) — Thiết kế bảng hỏi cho một nghiên cứu khoa học không phải là một điều dễ dàng. Để có thể cho ra một bảng hỏi đầy đủ và bao hàm đủ nội dung đôi lúc cần đến một đội ngũ chuyên gia hùng hậu và nhiều giờ làm việc chăm chỉ. Tác giả Ksenija Baždarić (Tổng biên tập tạp chí European Science Editing) trong bài viết Questionnaire structure - how much do editors need to know? trên tạp chí European Science Editing đã chia sẻ một số lời khuyên để giúp các nhà nghiên cứu có thể thực hiện một bảng khảo sát có cấu trúc tốt, tính khoa học cao, góp phần tăng thêm sức mạnh của nghiên cứu [1].

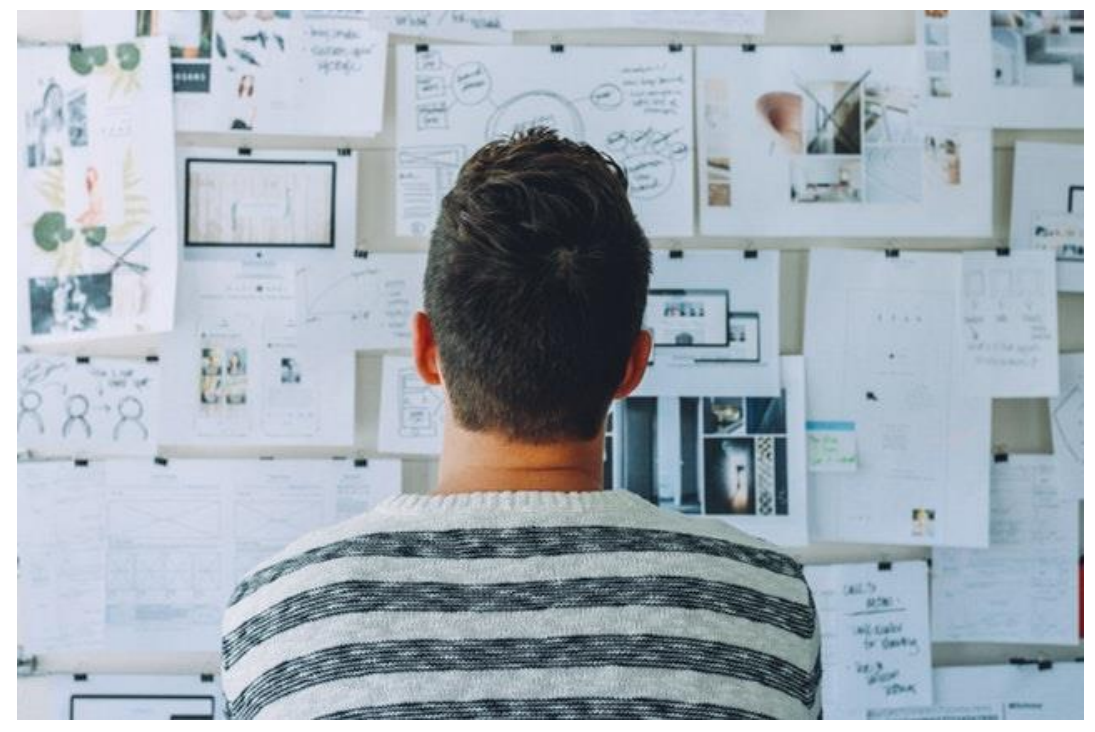

(Nguồn: $\underline{\text { Pexels) }}$

Trước tiên, sản xuất ra một bảng hỏi cần bắt đầu từ quá trình rà soát kĩ các nghiên cứu để có thể đặt ra các câu hỏi nghiên cứu trong một khung lý thuyết nhất định. Cần phải ghi nhớ mục đích chính của một bảng hỏi là để thử thách một lý thuyết. Chính vì thế, các câu hỏi cần phải đảm bảo một số yếu tố sau:

- Câu hỏi cần cụ thể và rõ ràng, tuyệt đối không mập mờ.

- Cần phải cân bằng số lượng câu hỏi tích cực và tiêu cực nếu bảng hỏi đo lường thái độ hoặc kiến thức.

- Thứ tự câu hỏi cũng cần được phân bố hợp lí. 
- Đối với một số câu hỏi cần đảm bảo khung thời gian chuẩn.

- Thang điểm 5 nấc Likert thường được sử dụng trong mọi trường hợp nhưng thực tế, thang điểm này chỉ được sử dụng để đo lường thái độ.

- Độ dài của một bảng hỏi sẽ phụ thuộc vào số lượng yếu tố cần được đo lường. Thông thường trong giai đoạn thai nghén đầu tiên, khoảng 10 - 15 câu hỏi cho mỗi thang đo là hợp lí.

Sau đó, bảng hỏi cần được thử nghiệm đối với một hoặc hai nhóm nhỏ để phát triển thêm bảng hỏi hoặc xác nhận bảng hỏi đủ điều kiện. Dữ liệu thu thập từ đợt thử nghiệm này cũng sẽ được phân tích để kiểm tra, đảm bảo bảng hỏi đạt chất lượng tốt nhất. Sau khi đã sản xuất ra phiên bản cuối cùng, sử dụng bảng hỏi để thu thập dữ liệu cần phải quan tâm đến tức số lượng người cần khảo sát và tỉ lệ trả lời.

Thông thường, số lượng người cần khảo sát cần lớn hơn từ 5 đến 10 lần số lượng câu hỏi trong bảng hỏi. Đồng thời những người được hỏi cũng cần đảm bảo tính đại diện của họ đối với toàn bộ dân số điều tra. Ví dụ dân số trẻ không thể trả lời thay thế cho dân số già, hay nhóm tốt nghiệp đại học không thể là đại diện cho nhóm chưa tốt nghiệp đại học.

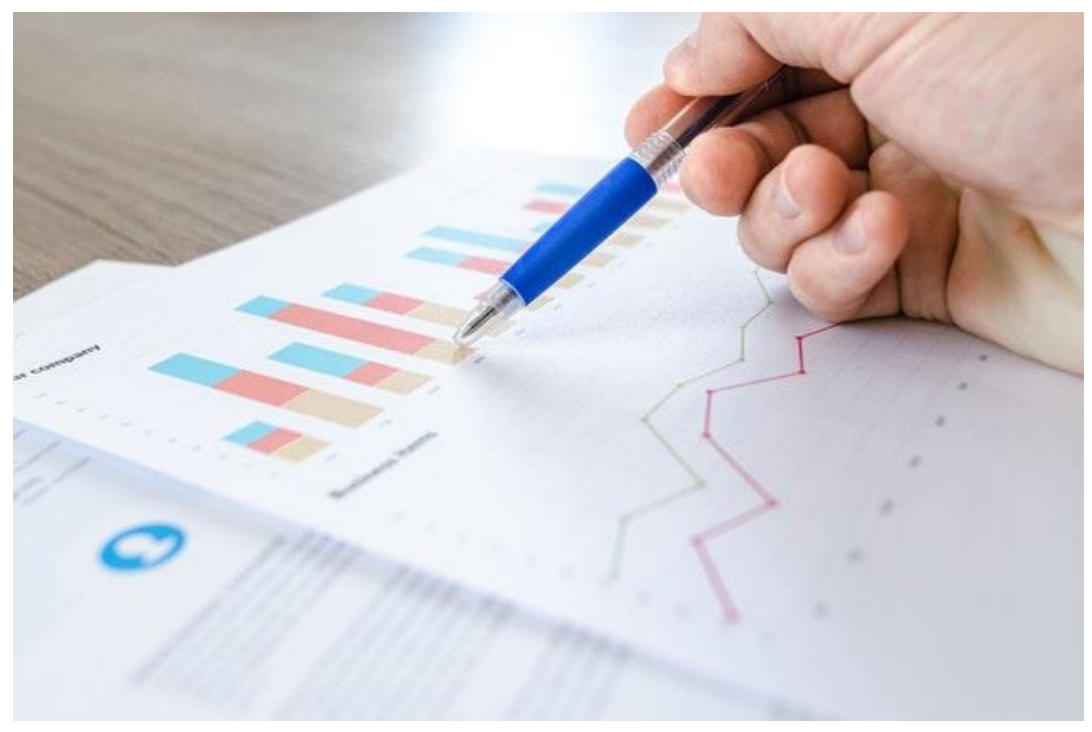

(Nguồn: Pexels)

Tỉ lệ trả lời cũng rất quan trọng, một số tạp chí yêu cầu tỉ lệ trả lời phải đạt trên $60 \%$ để đảm bảo tính đại diện của nhóm đối tượng được điều tra cũng như giảm thiểu vấn đề thành kiến của nhóm không trả lời. Đối với một số trường hợp có lí do đặc biệt thì cho việc tỉ lệ trả lời thấp thì cần nêu rõ và quyết định còn lại sẽ phụ thuộc vào biên tập.

Khi phân tích dữ liệu, cần phải trình bày đầy đủ số lượng trả lời cho mỗi câu hỏi. Các câu trả lời này sau đó sẽ được phân tích với mỗi biến có khả năng ảnh hưởng đến nó như giới tính hay mức thu nhập. Khi giải thích kết quả đã được đo lường bởi các thang đo khác nhau trong bảng hỏi, kết quả cần được chuyển đổi thành dạng z-values hoặc 
tổng hợp lại một cách tuyến tính. Bảng hỏi đo gián tiếp một lý thuyết và các thang đo chứa các biến liên tục. Chính vì thế kết quả thường là mối quan hệ giữa các biến và sử dụng các mô hình hồi quy khác nhau để phân tích.

Trong bản thảo nghiên cứu, quá trình xây dựng bảng hỏi, thu thập dữ liệu cần phải được trình bày kĩ càng, chuẩn mực nhất có thể trong phần Phương pháp luận. Kết quả thử nghiệm và xác nhận cũng nên được trình bày rõ ràng để đảm bảo người đọc có thể kết luận bảng hỏi được xây dựng tốt. Cuối cùng, trong xu thế mở [2] hiện nay thì việc công bố bảng hỏi ở phần phụ thêm nên được khuyến khích.

Nếu nghiên cứu mô tả một bảng hỏi mới được thiết kết thì tác giả cần nêu rõ lý do tại sao lại cần bảng hỏi mới. Biên tập viên cũng tham khảo ý kiến của một nhà bình duyệt về thống kê để kiểm tra quá trình thiết kế và xác nhận bảng hỏi. Ngoài ra, biên tập viên cũng nên có phần hướng dẫn cách thức tường thuật bảng hỏi rõ ràng trong hướng dẫn nộp bài của tạp chí.

Hy vọng các gợi ý này của tác giả Ksenija Baždarić sẽ giúp các bạn thực hiện nghiên cứu tốt hơn.

\section{References:}

[1] Baždarić, K. (2018). Questionnaire structure - how much do editors need to know?. European Science Editing, 44(4), 74-75, DOI: 10.20316/ESE.2018.44.18011.

[2] Vuong, Q. H. (2017). Open data, open review and open dialogue in making social sciences plausible. Nature: Scientific Data Updates (December 12). URL: <http://blogs.nature.com/scientificdata/2017/12/12/authors-corner-opendata-open-review-and-open-dialogue-in-making-social-sciences-plausible/>. 